\title{
Preparation, Characterization and Evaluation of Some Acrylate Polymers Nanoparticles as Binder to Improving the Physical Properties of Water Based Paints
}

\section{H Abd El-Wahab ${ }^{1 *}$, M Attia $^{2}$, WA Hassan ${ }^{3}$ and AM Nasser ${ }^{1}$}

${ }^{1}$ Chemistry Department, Faculty of Science, Al-Azhar University, Cairo, Egypt

${ }^{2}$ Al-Nada Company for Paints, 5th Settlement, Egypt

${ }^{3}$ Egyptian British Company for Polymers and Chemicals, 6th of October, Egypt

\begin{abstract}
Nano-emulsions have unique properties such as small droplet size, robust stability, translucent appearance and tunable rheology. These properties make nano-emulsions an attractive candidate for applications in the paints industry. Nano-emulsion were prepared by semi-continuous method and, then the prepared emulsion Co-polymer of Styrene/2 Ethylhexyl acrylate and Ter-polymer of Styrene/methyl methacrylate/2-Ethylhexyl acrylate formulated and used as a binder for waterbased paints to improve physical properties against (UV irradiation, heavy rain, and discoloration of paint). Characterization of the prepared emulsions was performed using e.g. FTIR, TEM, DSC, TGA, and DLS. Nano-emulsions formed by using two different surfactants (anionic and nonionic surfactant) in presence of $\mathrm{K}_{2} \mathrm{~S}_{2} \mathrm{O}_{8}$-initiation and caused to making two acrylic emulsion polymers. Based on formulated this prepared polymer and their use as a binder for paint. The adhesion, surface hardness, gloss brightness, and water resistance were studied and evaluated. Also, the purpose of this study is to improve UV irradiation by exploring the influence of different compositions on the stability of waterborne paints. And modification of the flow behavior and structure in predictable way to control sag resistance, storage stability, spatter resistance and application behavior.
\end{abstract}

\section{Keywords}

Nano-emulsion polymer, Ter-polymer water-based paints, 2-Ethylhexyl acrylate

\section{Introduction}

Nanoemulsions are kinetically stable liquidin-liquid dispersions with droplet sizes on the order of $100 \mathrm{~nm}$. Their small size leads to useful properties such as high surface area per unit volume, robust stability, optically transparent appearance, and tunable rheology. Nanoemulsions are finding application in diverse areas such as drug delivery, food, cosmetics, pharmaceuticals, and material synthesis. Additionally, they serve as model systems to understand nanoscale colloidal dispersions. High and low energy methods are used to prepare nanoemulsions, including high pressure homogenization, ultra-sonication, phase inversion temperature and emulsion inversion point, as well as recently developed approaches such as

*Corresponding author: H Abd El-Wahab, Chemistry Department, Faculty of Science, Al-Azhar University, Cairo, Egypt

Accepted: February 06, 2019; Published: February 08, 2019

Copyright: (c) $2019 \mathrm{El}$-Wahab HA, et al. This is an open-access article distributed under the terms of the Creative Commons Attribution License, which permits unrestricted use, distribution, and reproduction in any medium, provided the original author and source are credited.

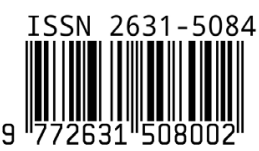

El-Wahab et al. Int J Nanoparticles Nanotech 2019, 5:022 
bubble bursting method. Also, nanoemulsions are emulsions with droplet size on the order of 100 $\mathrm{nm}$. A typical nanoemulsion contains oil, water and an emulsifier. The addition of an emulsifier is critical for the creation of small sized droplets as it decreases the interfacial tension i.e., the surface energy per unit area, between the oil and water phases of the emulsion. The emulsifier also plays a role in stabilizing nanoemulsions through repulsive electrostatic interactions and steric hindrance [1]. Extreme emulsification methods can be used to produce nanoscale dispersions of droplets of one liquid in another immiscible liquid. These microfluidic and ultrasonic approaches of rupturing larger microscale droplets into nanoscale droplets are providing interesting and useful non-equilibrium systems of structured liquids. Despite their metastability, nanoemulsions can persist over many months or years due to the presence of a stabilizing surfactant that inhibits the coalescence of the droplets. Although one might initially imagine that there are no significant fundamental differences between nanoemulsions and their microscale counterparts, in fact, the physical properties of nanoemulsions can be quite different from those of microscale emulsions, as we demonstrate herein. Nanoemulsions are part of a broad class of multiphase colloidal dispersions. Although some lyotropic liquid crystalline phases, also known as 'micellar phases', 'mesophases', and 'microemulsions', may appear to be similar to nanoemulsions in composition and nanoscale structure, such phases are actually quite different $[2,3]$.

In recent years, enormous efforts have been made to develop new waterborne coating with better performance. Recent findings have shown that incorporation nano-particles can play a signifi- cant role in the modification of waterborne coating $[4,5]$. Acrylic waterborne coatings are commonly used in the retail decorative market, industrial and building coatings [6]. Generally, in the case of styrene-acrylic co-polymers, the monomer styrene substitutes the methyl methacrylate (MMA) in the copolymer in order to increase the glass transition temperature. On the other hand, the presence of styrene reduces the film more vulnerable UV radiation, consequently, yellowing effect of this polymer is usually observed. Therefore, styrene-acrylic painted items for outdoor applications are disposed to photo-oxidation induced by the solar radiation. The photo-oxidation process can be described as a series of reaction staking place in the polymer chain from the rupture of double bonds leading to the embrittlement, discoloring and eventually crack formation on the film surface $[7,8]$. The stability of nano-emulsion polymers can continue for long months. The polymerization of these emulsions can begin with sub micrometer monomer droplets (100 $\mathrm{nm})$. The long chain surfactants penetrate less the oil-water interface than the small monomer molecules, thus the emulsifier molecules move closer together [9].

Acrylic coatings are yet another diverse class of organic coatings. Polyethylhexyl acrylate and polymethyl methacrylate polymers and copolymer blends comprise this class of resins. As a class of resins, acrylics are fast-setting, easily pigmented coatings that exhibit high gloss, good color retention and UV resistance. They are resistant to weathering but are not necessarily resistant to acids and alkalis. Given these characteristics, acrylics are used mainly in coatings for protection against outdoor exposure [10]. El-Sayed Negim and Co-workers [11] have prepared terpolymer of 2-ethylhexyl acrylate, methyl methacrylate and methacrylic acid
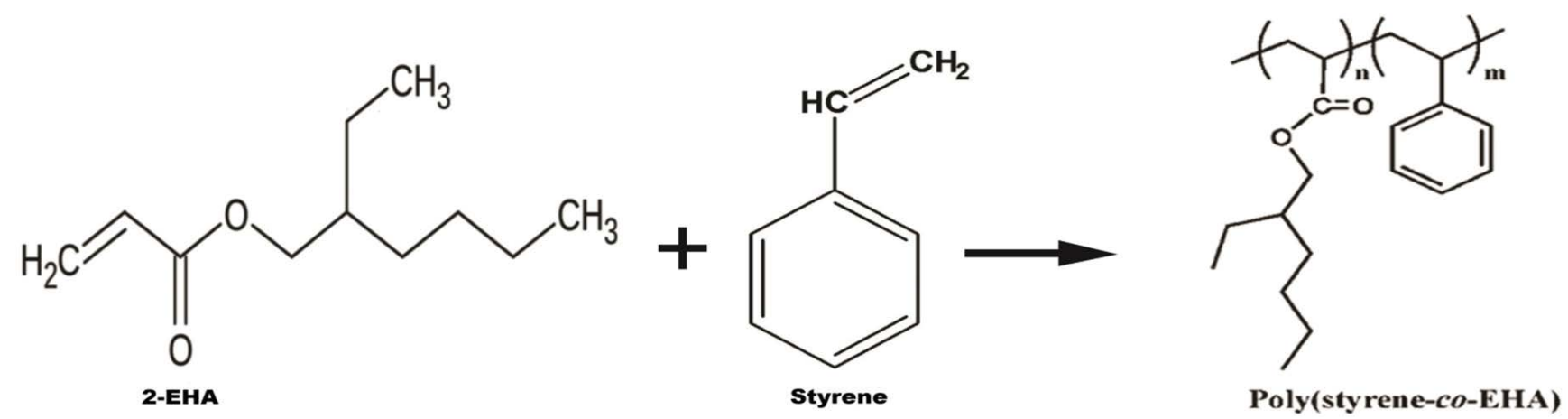

Scheme 1: Chemical structure of Copolymer Styrene and 2-Ethyl hexyl acrylate. 


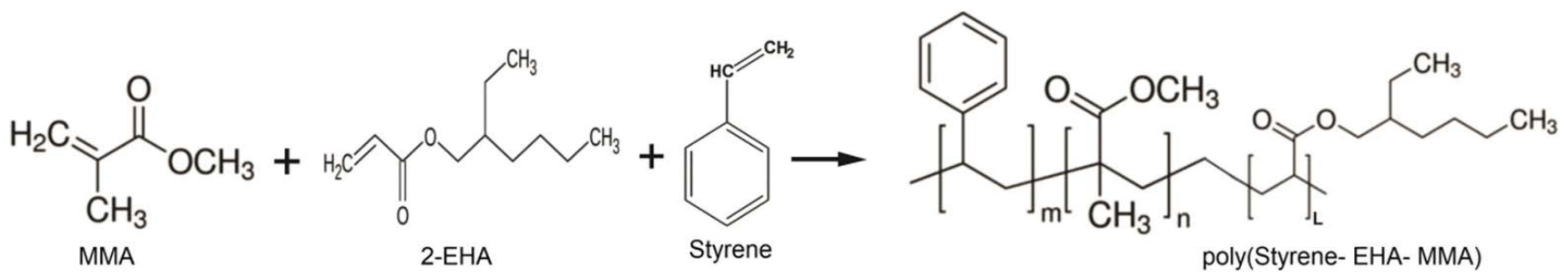

Scheme 2: Chemical structure of Ter-polymer Styrene, Methyl methacrylate and 2-Ethyl hexyl acrylate.

with different chemical composition ratios of MMA and 2-EHA could be used to form films having high bonding strength with concrete substrate. Copolymerization of styrene and 2-EHA and Ter-polymerization of styrene, methyl methacrylate (MMA) and 2-Ethylhexyl Acrylate (EHA). Shown in Scheme 1 and Scheme 2.

The main objective of our work was concerned to use efficient combinations of anionic surfactants to produce stable nano-latexes of Co-polymer and Ter-polymer which can be used as a binder to improving the physical and mechanical properties of water based paints for example (Viscosity, Storage stability, rub out test water resistance, scrub resistance and gloss).

\section{Materials and Methods}

\section{Chemicals and materials}

Styrene, Methyl methacrylate, 2-Ethylhexyl acrylate, acrylic acid and acrylamide were supplied from Sigma-Aldrich Company, USA. Desponil LDPS 25, Texapone (Basf chemical company, GMBH) were used as anionic surfactants. TergitolNP30 (Dow chemicals company, USA) was used as nonionic surfactant. Potassium per sulfate (KPS) from AKKIM Company, Turkey, was used as initiator. Sodium acetate and ammonium hydroxide (EI-Nasr Chemicals Company, Egypt) were used as pH stabilizers. Titanium dioxide (under the trade name Tioxide TR-90, Huntsman Company, UK) was used as the main pigment. Texanol 2, 2, 4-trimethyl-1, 3-pentanediol monoisobutyrate (Eastman Chemical Company, USA). Propylene glycol (RecochemInc, Australia) were used as coalescing agent. Anti-foaming agent used is AGITAN301 (MünzingChemie, Germany), the antibacterial agent is Acticide HF was purchased from THOR, and the associative thickener used is Rheolate 125 (Elementis Specialties, Germany). The concentrated pigments solutions used in this work are commercial products and have been supplied by (Tinting System Com- pany, KSA). The concentrated pigments solutions were: Green (LS), Blue (MS) and black pigments (TT). The pigments solutions were based on organic compounds. A commercial latex binders (Styrene acrylate) PEXICRYL SA5000 and (Vinyl acrylate) PEXICRYL VAA500, were supplied by PEXICHEM, India.

\section{Polymerization procedure}

Pre-emulsion preparation: Distilled water, ionic surfactant and monomers were added into a glass beaker equipped with high speed homogenizer (Ultra-Turax homogenizer) for $30 \mathrm{~min}$. The monomers acrylic acid and acrylamide were added with continuous homogenizing

Polymerization procedure: Polymerization was carried out in $1 \mathrm{~L}$ stainless steel reactor fitted with reflux condenser, thermometer and a mechanical stirrer. The temperatures of homogenization and polymerization were 25 and $80^{\circ} \mathrm{C}$, respectively and nitrogen was purged during the polymerization step. During the process, it's included the following steps:

1. Pre-emulsion containing styrene, 2-EHA, acrylic acid and acrylamide was emulsified by (Texapone and Desponil LDPS 25) in little amount of de-ionized water and homogenized for $30 \mathrm{~min}$ at speed $1000 \mathrm{rpm}$.

2. Dissolve the Initiator (KPS) in a small quantity of de-ionized water.

3. $5 \%$ of pre-emulsion was seeded to the reactor, containing; de-ionized Water, nonionic surfactant NP30 and pH regulator, during 15 min with low speed mechanical agitator $(100 \mathrm{rpm})$ and at 80 ${ }^{\circ} \mathrm{C}$. The allowed time for micelle formation was an additional $15 \mathrm{~min}$.

4. Afterward, the pre-emulsion was added to the reactor through dropping funnel in $175 \mathrm{~min}$.

5. In steps 3 and 4 , a continuous dropping of the initiator solution was performed in the reactor. 
6. At the end of addition of all ingredients, polymerization was allowed to continue for an additional $3 \mathrm{~h}$, and then the reactor was held at 80 ${ }^{\circ} \mathrm{C}$ for 1 hour to remove any free monomer.

7. The reactor was then cooled to $30^{\circ} \mathrm{C}$ and the
$\mathrm{pH}$ adjusted to 8 using ammonia solution. Following neutralization, the addition of biocide to the latex was undertaken and then the material was filtered with a 100 mesh filter and collected [12-14]. The formulation of the latexes synthesis is shown in Table 1.

Table 1: The recipe for the poly (St/EHA), and poly (St/MMA/EHA) latexes.

\begin{tabular}{|l|l|l|}
\hline Raw materials & Weight \% & \\
\hline Initial reactor charge & Co-polymer (St/EHA) & Ter-polymer (St/MMA/EHA) \\
\hline De-ionized water & 37.2 & 0.4 \\
\hline NP30 (non-ionic emulsifier) & 0.4 & 0.1 \\
\hline Sodium acetate (pH stabilizer) & 0.1 & 21.6 \\
\hline Monomer mixture (4 h feed) & 31.6 & 10 \\
\hline Styrene & ----- & 18.4 \\
\hline Methyl methacrylate & 18.4 & 2 \\
\hline 2-Ethyl Hexyl Acrylate & 2 & 0.5 \\
\hline Acrylic acid & 0.5 & 2.5 \\
\hline Acrylamide & 2.5 & 0.5 \\
\hline Desponil LDPS 25 & 0.5 & \\
\hline Texapone & & 0.3 \\
\hline Initiator mixture (4 h feed) & 0.3 & 6.5 \\
\hline KPS (initiator) & 6.5 & 51.5 \\
\hline De-ionized water & & 96 \\
\hline Specifications & 53 & 18000 \\
\hline Solid content \% & 97.5 & 26000 \\
\hline Gravimetric conversion \% & & \\
\hline Viscosity cp & & \\
\hline
\end{tabular}

Table 2: The recipe for latex paints preparations.

\begin{tabular}{|c|c|c|c|}
\hline \multirow[t]{2}{*}{ Composition } & \multicolumn{3}{|l|}{ Weight \% } \\
\hline & Function & High PVC & Low PVC \\
\hline Water & solvent & 30 & 20.075 \\
\hline Acticide HF & Biocide & 0.15 & 0.15 \\
\hline \multicolumn{4}{|l|}{ Add under stirring } \\
\hline Tylose HEC & Thickening agent & 0.4 & 0.125 \\
\hline Dispex A40 & Dispersing agent & 0.5 & 1 \\
\hline Agitan 301 & Defoamer & 0.3 & 0.5 \\
\hline Ammonia & $\mathrm{pH}$ adjustment & 0.2 & 0.2 \\
\hline Tioxide 88 & pigment & 10 & 22.5 \\
\hline ROPAQUE $^{\mathrm{TM}}$ Ultra EF & Opacity polymer & --- & 5.5 \\
\hline Snowhite 80 & Extender & 7.5 & --- \\
\hline Calcium carbonate $5 \mu \mathrm{m}$ & Filler & 30 & --- \\
\hline \multicolumn{4}{|l|}{ Grind for $25 \mathrm{~min}$. at $14 \mathrm{~m} / \mathrm{s}$} \\
\hline \multicolumn{4}{|c|}{ Reduce mixer speed to $10 \mathrm{~m} / \mathrm{s}$ Add under stirring } \\
\hline Agitan 301 & Defoamer & 0.2 & 0.3 \\
\hline Acticide HF & Biocide & 0.15 & 0.15 \\
\hline Binder & Styrene acrylate & 12.5 & 42.5 \\
\hline Texanol & Coalescing agent & 0.5 & 1 \\
\hline Glycol & Co-solvent & 0.5 & 0.5 \\
\hline RHEOLATE $^{\circledR} 125$ & Rheological additive & 0.3 & 0.7 \\
\hline Water & solvent & 6.8 & 4.8 \\
\hline Total & & 100 & 100 \\
\hline
\end{tabular}




\section{Preparation of latex paints formulations}

Evaluation of the high solid content Nanoemulsion Co-polymer and Ter-polymer latexes as a binder in waterborne house-hold paints was carried out and compared with commercial binders. In order to obtain latex paints, a high-speed disperser with working range from $2000 \mathrm{rpm}$. The amount of water determined in the formulation was added where the dispersing and thickening agents had been previously added. The disperser speed was increased up to $2000 \mathrm{rpm}$. After that, the remaining pigments and additives were selectively added. Finally, the disperser speed was decreased, and the latex dispersion was added slowly so as to obtain full formulation homogenization. The formulations of paints preparation is listed in Table 2.

\section{Characterization}

Latex and dry latex film characterization: To characterize latex and dry latex film and obtain extensive information from experiments, qualitative and quantitative perception of emulsion polymerization process were gained as follows:

a) Fourier transform infrared (FT-IR): The polymer composition of the dried samples was identified by FT-IR analysis. The instrument utilized was a JASCO FTIR 6100 covering the wavelength range of $4000 \mathrm{~cm}^{-1}-400 \mathrm{~cm}^{-1}$.

b) Thermal analysis: Thermal analysis for the prepared materials has been carried out at Thermal Analysis unit, Central service labs, (NRC) using Diamond DSC Perkin Elmer, USA. And a Shimadzu TGA-50 thermo gravimetric analyzer, Columbia, EUA, in a nitrogen atmosphere using a heating rate of $10{ }^{\circ} \mathrm{C} / \mathrm{min}$ in the range between room temperature and $600{ }^{\circ} \mathrm{C}$.

c) Transmission electron microscopy (TEM): The morphology of the polymer particles was examined using transmission electron microscopy. In TEM the dry sample has to be transferred into an ultra-high vacuum and is exposed to DLS for a high energy beam of electrons (for example100 keV).

d) Dynamic light scattering: The particle size and particle size distribution of the prepared polymers were determined by dynamic light scattering, using a Malvern Zetasizer Nano, UK. This instrument was used to measure the hydrodynamic size in the range of $0.4 \mathrm{~nm}-10000 \mathrm{~nm}$. The number of single measurements of particle size was calculated as the average of the experimental determinations.

e) Viscosity measurement: The viscosity was measured using a Brookfield RVDVE-II+Pro Viscometer at different shear rates [15] according to ISO 2555.

Dry latex paint film characterization: Before characterizing the mechanical properties of the prepared dry latexes paint films were carried out by SIMIX four sides Film Applicator.

a) Digital Krebs Viscometer: For determining the viscosity of emulsion paint, the viscosity of the prepared paint samples was measured using a digital viscometer manufactured by the Sheen Company, which is normally used to measure paint formulations.

b) Gloss test: Gloss-meter Paint samples were applied on glass panels and left to dry for 48 hours before undertaking gloss measurements using a mini-gloss $60^{\circ}$ gloss-meter manufactured by the Sheen Company. According to ASTM D523 test [16].

C) Wet scrub resistance: Washability test Paint samples were applied on plastic panels and left to dry for one week prior to undertaking the washability test procedure. This involved placing the paint panel into the wet abrasion scrub tester (Sheen abrasion and washability tester) according to ASTM D4213 [17].

d) Water resistance: To study the water-resistant behavior of the coatings, water immersion test was conducted according to ASTM D870, three samples of coating were immersed in distilled water at $25^{\circ} \mathrm{C}$ for $358 \mathrm{~h} \mathrm{[18].}$

e) Weathering test: Accelerated weathering test was evaluated in the QUV weathering tester equipment model QUV/Se, the samples were submitted to ageing for $300 \mathrm{~h}$. Visual observations were made and any unusual observations were recorded [19].

f) Color matching test: Delta $E$ of the dray film by Color Spectrophotometer and Color Matching. Hangzhou CHNSpec Technology Co, Ltd. China.

\section{Result and Discussion}

\section{The effect of the emulsifier's mixture on the latex properties.}

Semi-continuous emulsion polymerization of Co-poly (St/EHA) and Ter-polymer (St/MMA/EHA) were performed in the presence of two anionic sur- 
Table 3: The influence of the emulsifier type on the latex properties.

\begin{tabular}{|l|l|l|l|}
\hline Emulsifier type & Reaction status & Appearance & Storage stability of $\mathbf{6}$ months \\
\hline Texapone & Stability & Milky and slightly bluish & Well \\
\hline Desponil LDPS 25 & Stability & Bluish and slight semi clear & Well \\
\hline Texapone and Desponil LDPS 25 & Stability & Semi clear and bluish & Very well \\
\hline
\end{tabular}

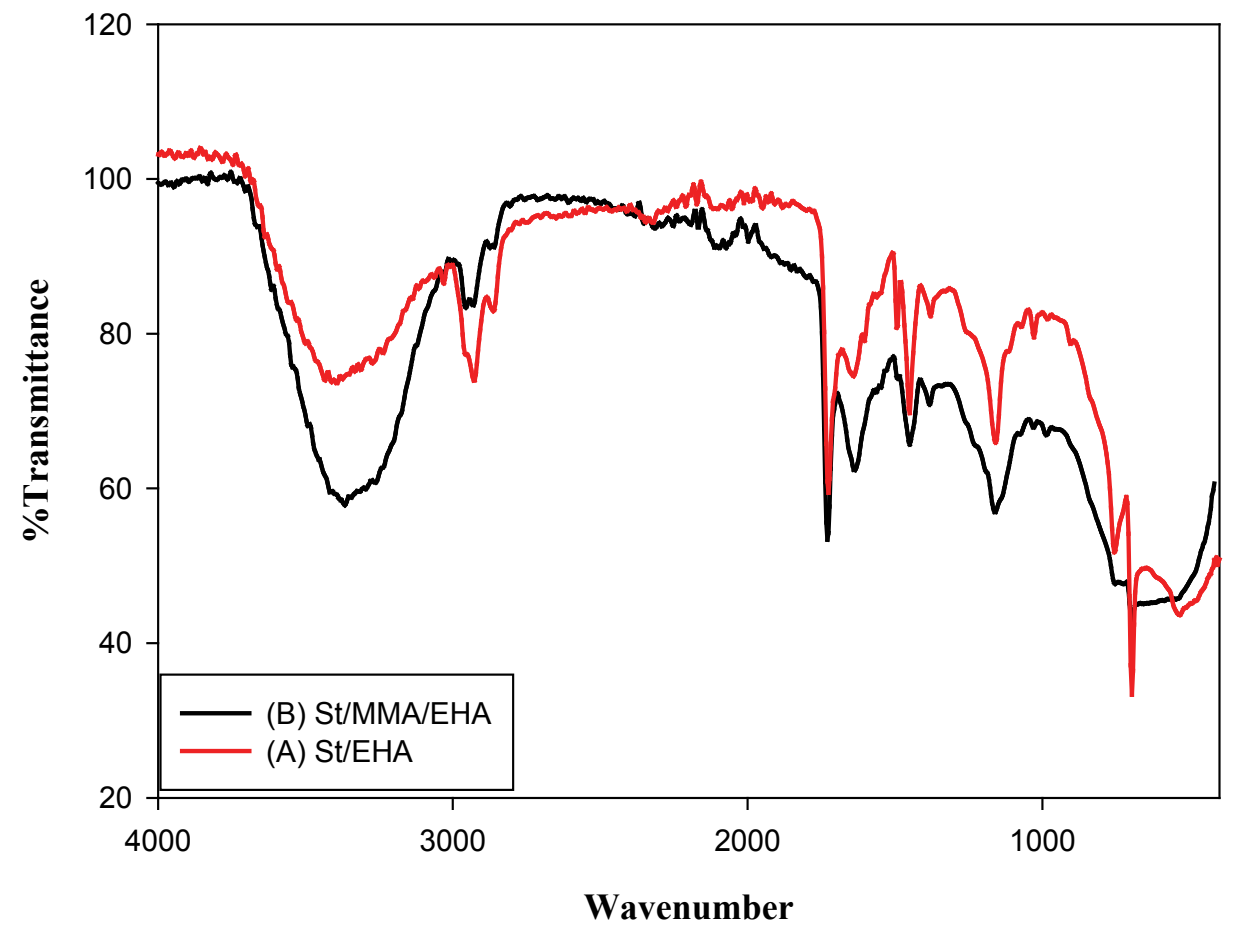

Figure 1: FTIR spectra of the prepared polymers.

factants combination with a non-ionic surfactant often results in more stable colloidal dispersions due to the synergistic effect [20]. The effects of different type of Desponil LDPS 25 and Texapone are shown in Table 3. Based on this table, it is clear that the bluish latex and clarity appearance obtained by mixing Desponil LDPS 25 and Texapone in the polymerization process. The effect of the emulsifier mixture concentration on the emulsion stability was also investigated, which revealed that latex stability increased with the increase of the emulsifier mixture concentration. This could be due to increasing the emulsifier mixture concentration which increased the number of micelles formed and increased the speed of the initiation and the rate of reaction, so the latex particle size decreased [21].

\section{Latex and dry latex film characterization of the prepared nano-polymers}

\section{FTIR spectroscopy:}

A. FTIR spectroscopy of the prepared Copolymer (St/EHA): The FTIR spectrum of the (St/
EHA) Co-polymer latex produced by emulsion polymerization is shown in Figure $1 \mathrm{~A}$. As clearly seen, the intensity of $\mathrm{O}-\mathrm{H}$ stretching vibration of carboxylic groups which appeared in the range $3410 \mathrm{~cm}^{-1}$, the higher wavenumbers $\mathrm{C}-\mathrm{H}$ aliphatic stretching around 2960, 2927, $2866 \mathrm{~cm}^{-1}$. The strong peaks around 1488 and $1451 \mathrm{~cm}^{-1}$ that are attributed to the aromatic $\mathrm{C}-\mathrm{C}$ skeletal ring near 1726,1641 , are assigned to $\mathrm{C}=\mathrm{O}$ bond. The peaks detected near 1603 and $1159 \mathrm{~cm}^{-1}$ are respectively attributed to the stretching vibration mode $\mathrm{C}=\mathrm{C}$, and $\mathrm{C}-\mathrm{O}-\mathrm{C}$ bonds [22].

B. FTIR spectroscopy of the prepared Terpolymer (St/MMA/EHA): The FTIR spectrum of the (St/EHA/MMA) Ter-polymer latex produced by emulsion polymerization is shown in Figure $1 \mathrm{~B}$. As clearly seen, $\mathrm{C}-\mathrm{H}$ aromatic stretching between 3100 and $3000 \mathrm{~cm}^{-1}, \mathrm{C}$-Haliphatic stretching at 2956 and $2870 \mathrm{~cm}^{-1}, \mathrm{C}=0$ stretching at about $1728 \mathrm{~cm}^{-1}$, the sharp absorptions at $1605 \mathrm{~cm}^{-1}$ due to skeletal $\mathrm{C}-\mathrm{C}$ aromatic stretching, $\mathrm{C}-\mathrm{O}$ and $\mathrm{C}-\mathrm{C}$ stretching at $1161,1119,1070,1030$, and $950 \mathrm{~cm}^{-1}$, aromatic 

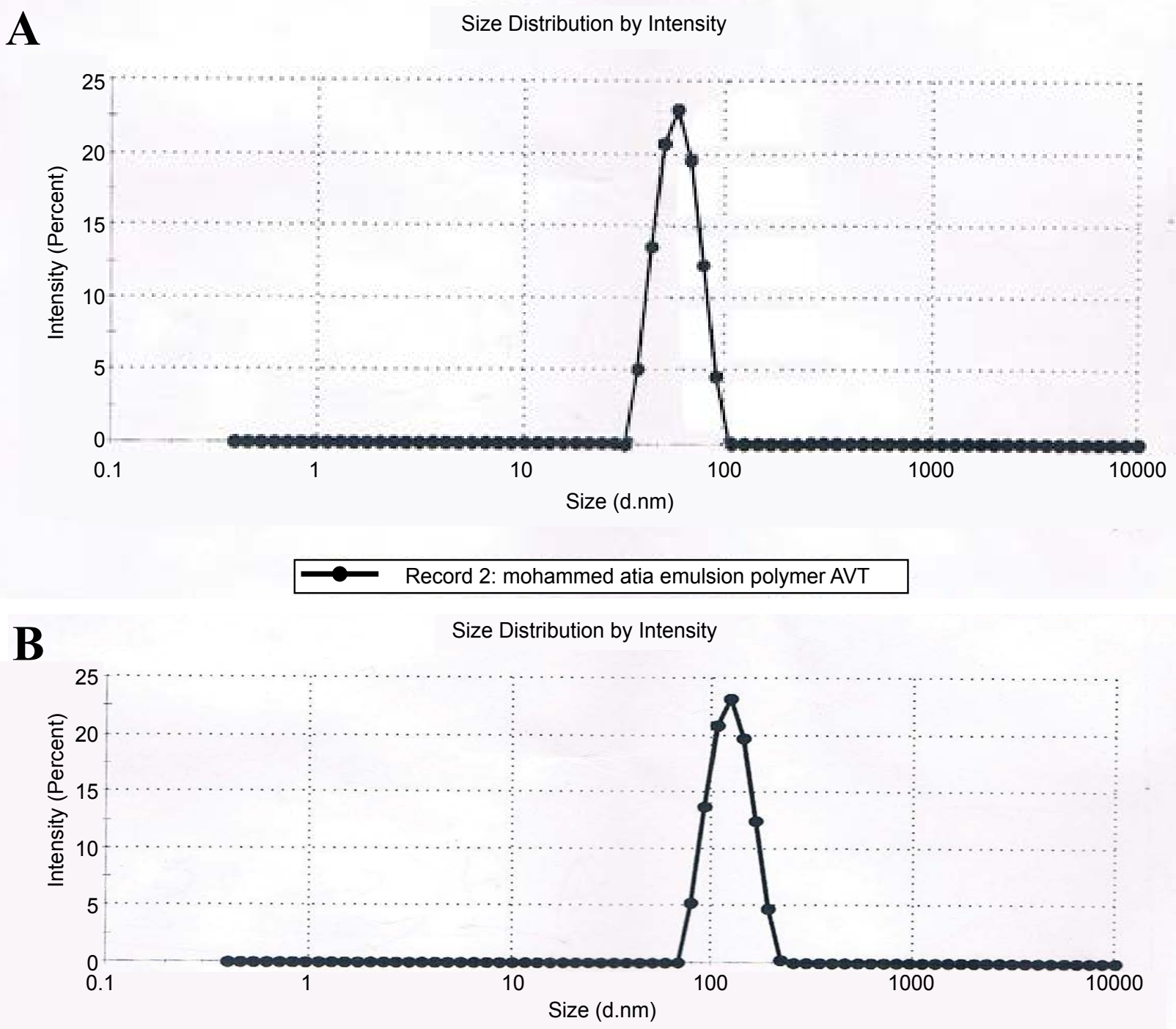

Record 3: mohammed atia emulsion polymer AVT
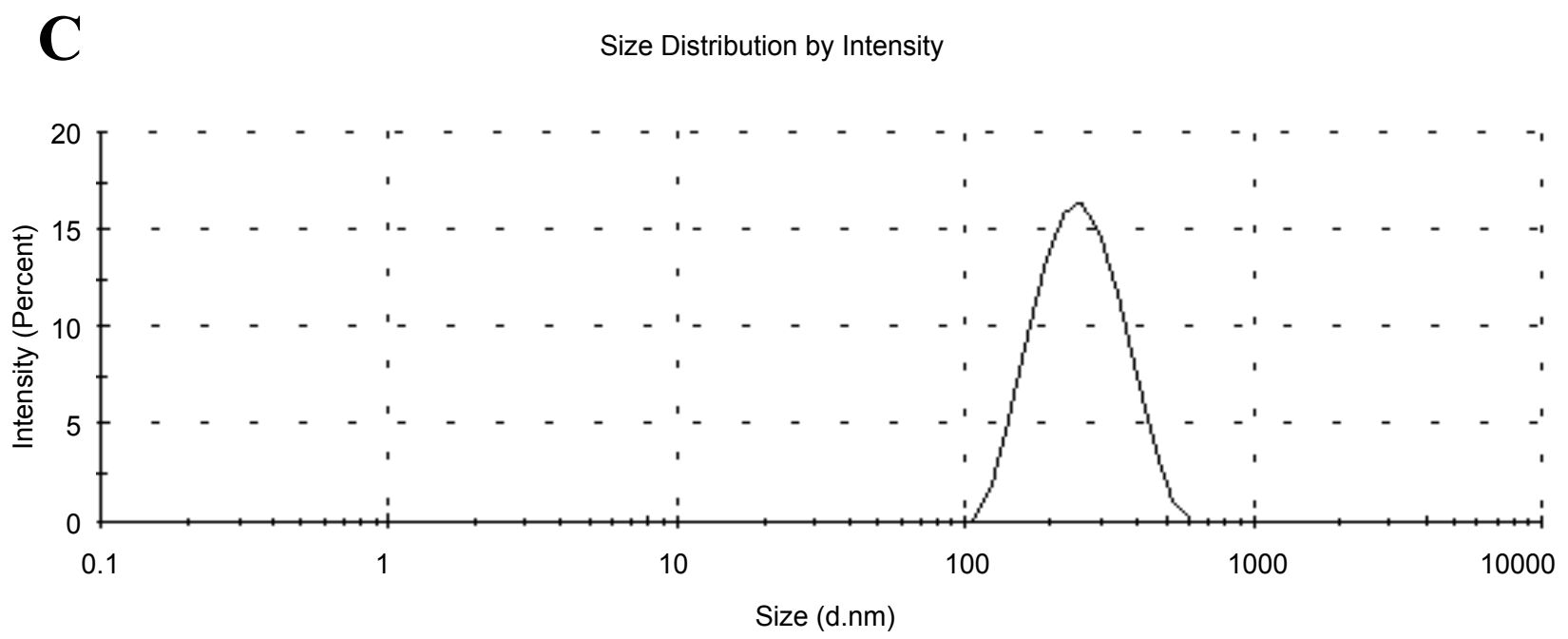

Figure 2: The average diameter of the prepared and commercial binder by DLS size distribution technique.

$\mathrm{C}-\mathrm{H}$ out-of-plane bending around $696 \mathrm{~cm}^{-1}$ [23]. deformation vibration bands are clearly observed Moreover, the peak at $1161 \mathrm{~cm}^{-1}$ is related to at $1450-1382 \mathrm{~cm}^{-1}$. $\mathrm{C}-\mathrm{O}-\mathrm{C}$ stretching vibration of ester group. The $\mathrm{CH}_{2}$ 
Dynamic light scattering (DLS): Particle size has directly an impact on the physical stability of emulsions. Reduced particle size lets more particles to be distributed on the boundary, yielding a more stable emulsion [24]. In the particle size and size distribution tests, the emulsion samples were diluted with water and measurements carried out immediately. The DLS chart of the nano Co-polymer was shown in Figure 2A. The average diameter of nano-Copolymer was calculated $95 \mathrm{~nm}$ with $100 \%$ intensity for the nanoparticles. Also, the DLS chart of the nano Ter-polymer was shown in Figure 2B. and the average diameter of nano Ter-polymer calculated as $120 \mathrm{~nm}$ with $100 \%$ intensity. In nano Ter-polymer we observed that, increase in particle size and the same intensity, and all of particles convert to final nanopolymer. The DLS chart of commercial polymer was shown in Figure 2C. The average diameter of the particles of commercial polymer was $220 \mathrm{~nm}$ with $100 \%$ intensity.
Morphology of the prepared polymers: The determination of particle size in emulsion polymer latexes is very important as they affect other properties of the latexes (e.g., stability, rheology, optical, and electrical). It is important to mention that with increasing the mean particle size of the latex, the colloidal stability will decrease [9]. TEM analysis of the Latexes produced by emulsion polymerization was carried out and is shown in Figure $3 \mathrm{~A}$ and Figure 3B. Interestingly, in Figure $3 A$, the morphology of the Co-polymer (St/EHA) is observed. A bright thick shell rings around the seeds for the latex particles were obviously observed. The dark component could be attributed to core while the lighter component could be due to the acrylic copolymer shell. In some particles, the boundaries between the shell and core were much less distinct which could mean that there is greater mixing ratio of the Styrene-2-Ethylhexyl acrylate to prepare stable nano-polymer. A similar variety of structures

(A)

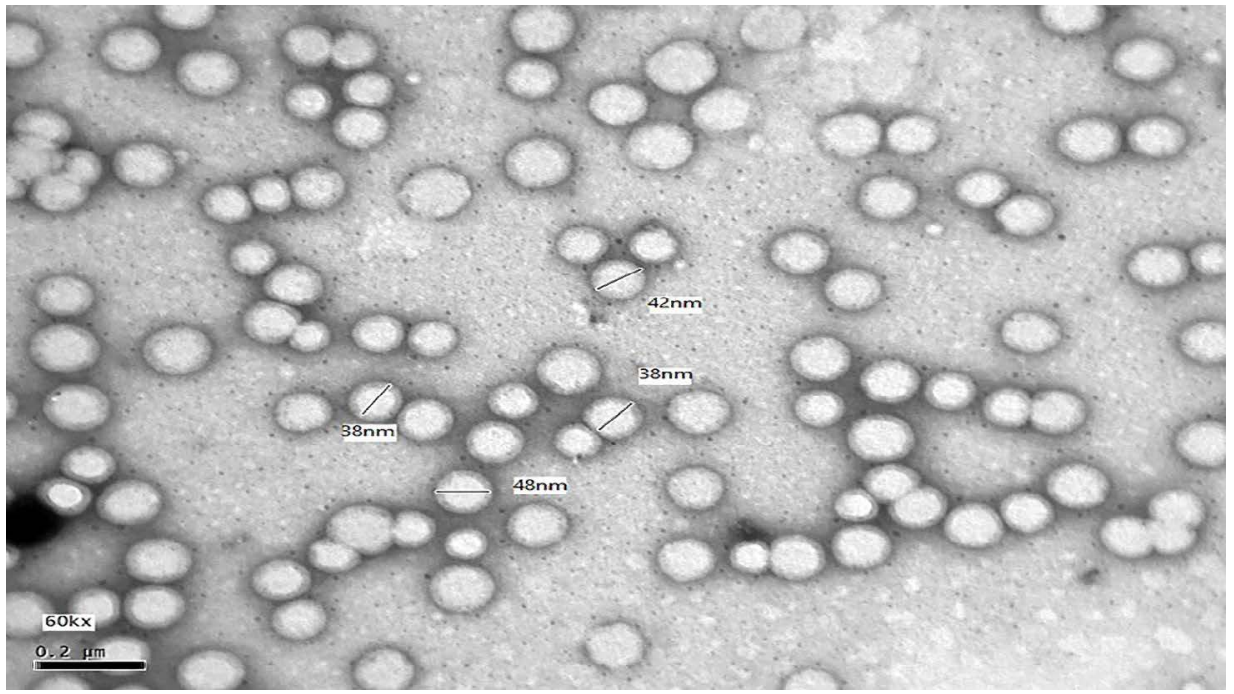

(B)

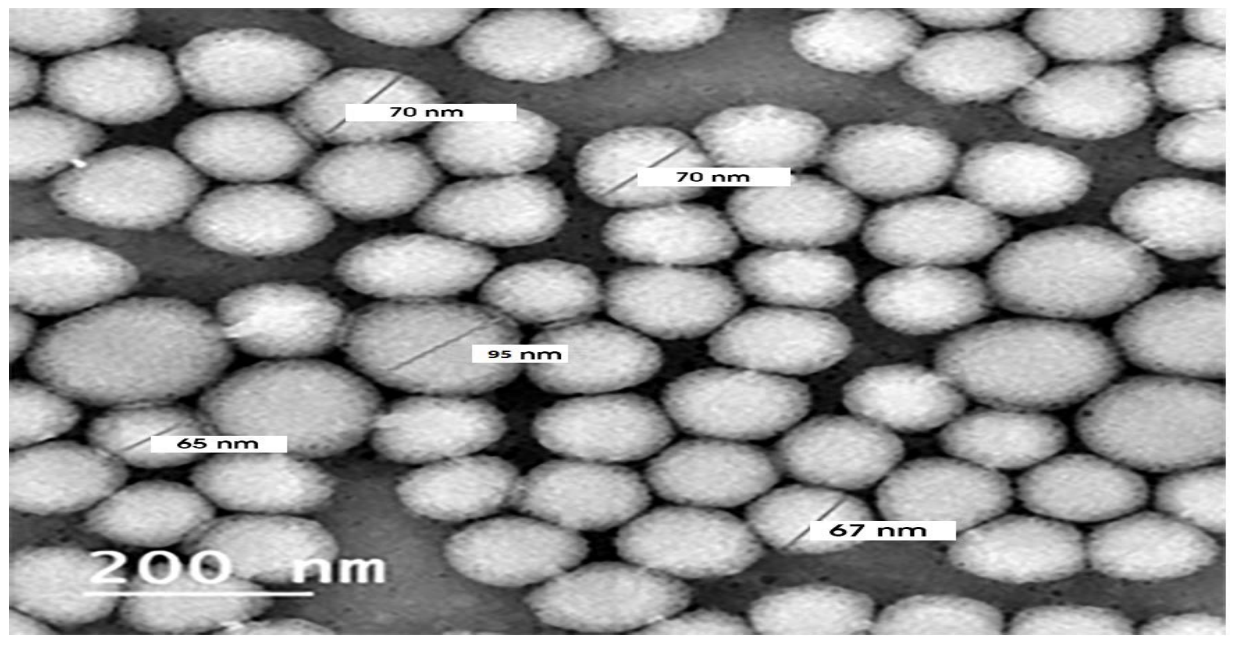

Figure 3: TEM photographs of A) St/EHA Co-polymer; B) St/MMA/EHA Ter-polymer. 
were found for the latex particles are shown in Figure 3B, with some particles having a uniform structure and mono-dispersed spherical particles. Tem images are shown in Figure 3. Which have an average diameter of (38-65 $\mathrm{nm}$ ).

\section{Thermal properties of all prepared latex films:}

Thermogravimetric analysis (TGA): TGA is a very important technique used to determine the thermal stability of materials. The TGA curves of all prepared dry latexes films are indicated in Figure $4 \mathrm{~A}$ and Figure $4 \mathrm{~B}$. The curves show that the degradation is completed in one step. Table 4 represents the decomposition step and percentage mass loss for all films.

TGA curves cover a wider temperature range $\left(363-500{ }^{\circ} \mathrm{C}\right.$ ) including the melting point, physical transition and the thermal degradation of all prepared films. The values of percentage mass loss in the decomposition step indicate the existence of a chemical degradation process [25] resulting from bond scission (carbon-carbon bonds) in the polymeric backbone. Comparing TGA curves of both (St/EHA) dry latex film and (St/MMA/EHA) dry latex film, slight difference was noticed. Both Co-polymer and Ter-polymer exhibited the same final decomposition temperature $\left(500{ }^{\circ} \mathrm{C}\right)$ but at different weight loss\%. Both Co-polymer (St/EHA) and Ter-polymer (St/MMA/EHA) decomposed exhibiting thermal events that followed. The initial decomposition temperature of both of them was observed at 380 and $363{ }^{\circ} \mathrm{C}$, respectively. The final decomposition temperature was at 407 and 396.5 ${ }^{\circ} \mathrm{C}$, respectively.

Weight losses were 94.5 and $91.6 \%$, respectively. This means that Co-polymer (St/EHA) is slightly more stable than Ter polymer (St/MMA/EHA). This means that the chemical structure played an important role in the thermal decomposition process [26].

Differential Scanning Calorimetry (DSC): Although the polystyrene (PSt) is less compatible with a huge number of polymers [27]. The DSC thermo grams of St/EHA Figure 5A and St/MMA/

Table 4: TGA data for dry films.

\begin{tabular}{|l|l|l|l|l|}
\hline Dry latex & Region decomposition & Start temperature ${ }^{\circ} \mathrm{C}$ & End temperature ${ }^{\circ} \mathrm{C}$ & Weight loss \% \\
\hline St/EHA & One step & 380 & 407 & 94.5 \\
\hline St/MMA/EHA & One step & 363 & 396.5 & 91.6 \\
\hline
\end{tabular}

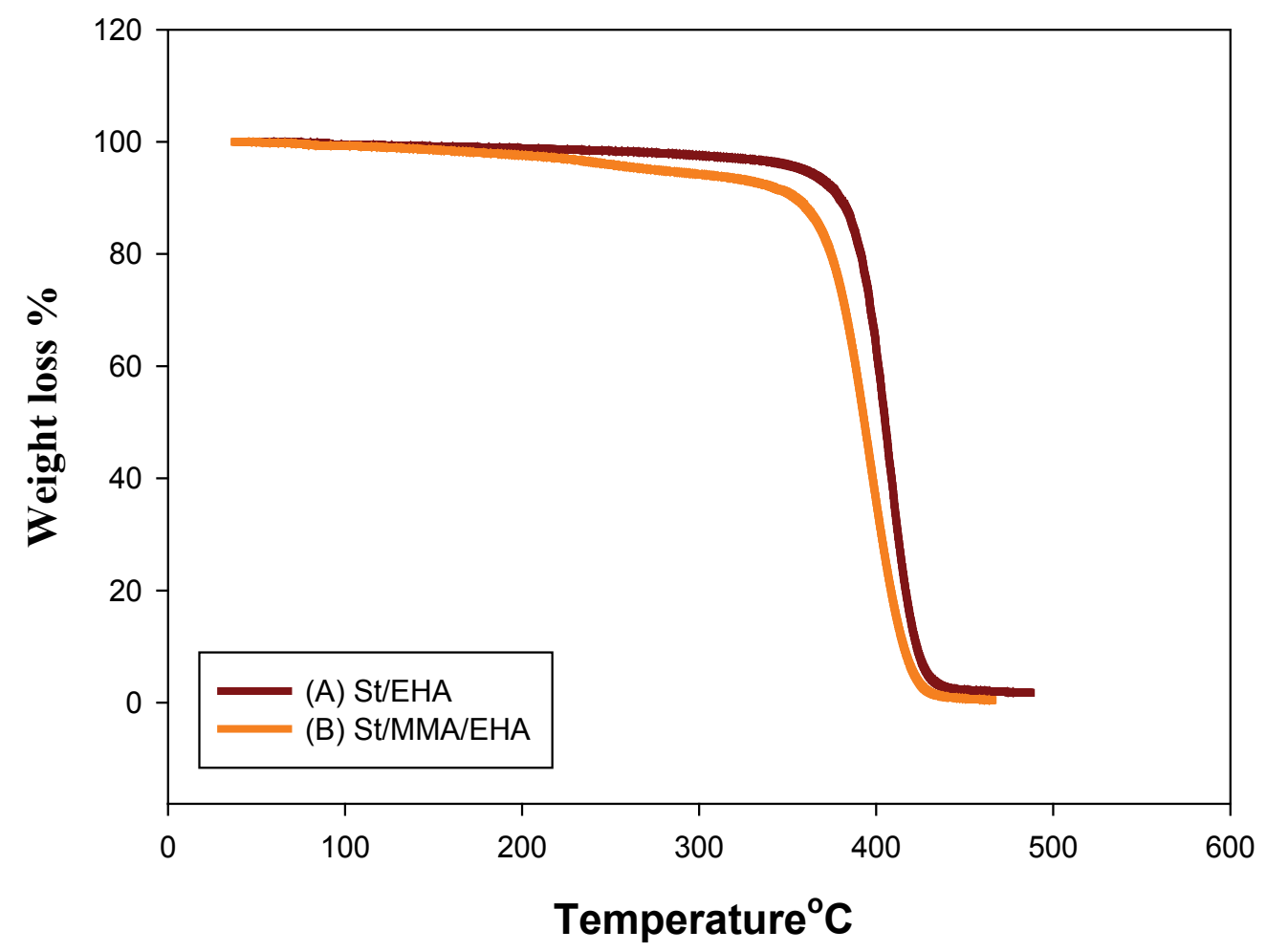

Figure 4: TGA thermograms for prepared dry latexes films. 


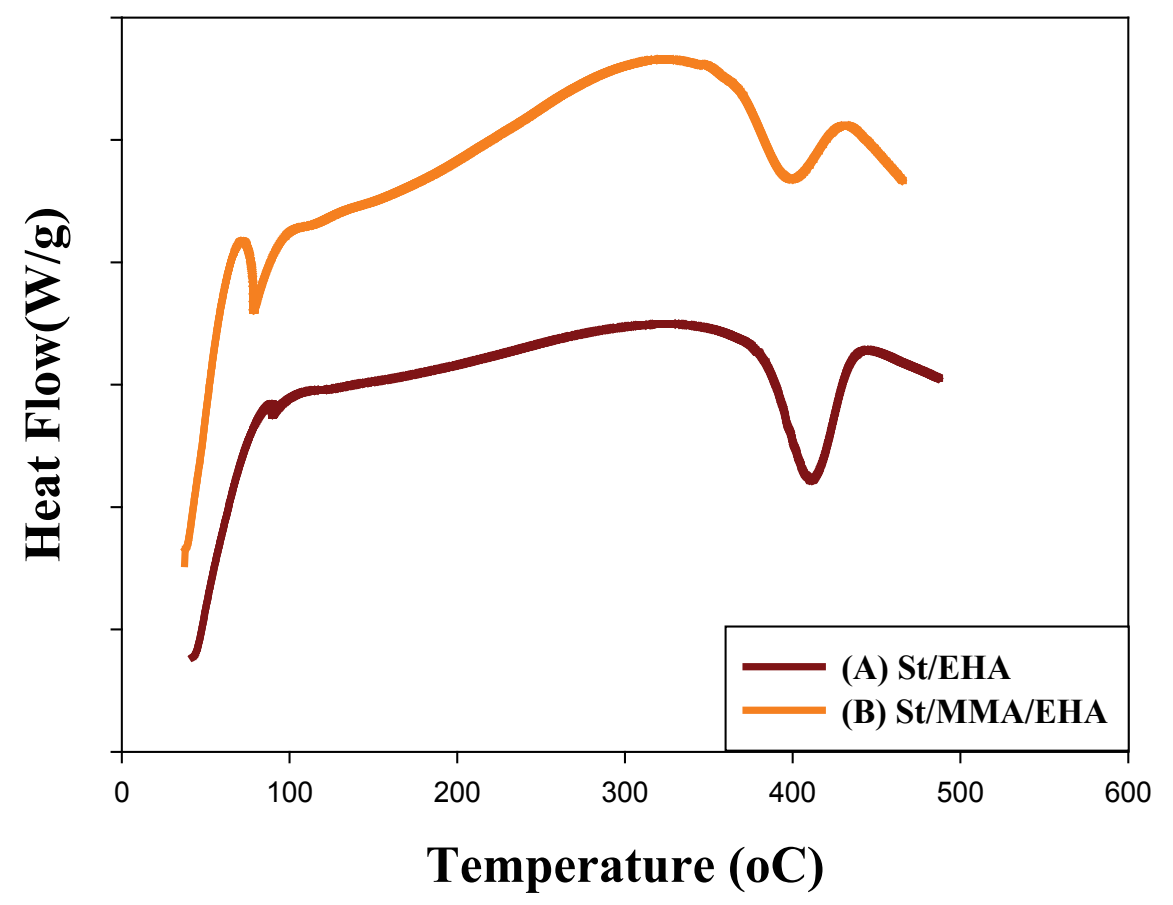

Figure 5: DSC thermograms of the prepared polymers.

EHA Figure $5 \mathrm{~B}$ exhibit one melting point at $410.5^{\circ} \mathrm{C}$ and $396.9^{\circ} \mathrm{C}$, respectively. This indicates that the Styrene is high compatible with both 2-Ethylhexyl acrylate and Methyl methacrylate. As observed the melting point ( $\mathrm{Tm}$ ) of Ter-polymer (St/MMA/EHA) is decreased corresponding to the phase of methyl methacrylate (MMA) is existence. This is respect to the hydrophobicity of methyl methacrylate (MMA) is more than Ethylhexyl acrylate (EHA). Therefore, the more polar latexes (e.g. those St with MMA) possess an amount of bonded water higher than those less polar (e.g. those St with EHA). The amount of water bonded in both (St/EHA and St/ MMA/EHA) given a broad DSC peak at $105{ }^{\circ} \mathrm{C}$ and 108. On the other hand, by compared to the amount of heat enthalpy $(\Delta \mathrm{H})$ of (St/EHA and St/ $\mathrm{MMA} / \mathrm{EHA}$ ), it indicates that the amount of water absorbed by St/MMA/EHA latex is higher than St/ EHA latex. This bounded water lead to decrease in the melting point of (St/MMA/EHA) Ter-polymer latex. The enthalpy value $(\Delta \mathrm{H})$ of (St/EHA) Copolymer and (St/MMA/EHA) Ter-polymer was $440.3 \mathrm{~J} / \mathrm{g}$ and $273.5 \mathrm{~J} / \mathrm{g}$, respectively. The DSC data showed that the $(\Delta \mathrm{H})$ decreased as the presence of MMA. It was probably due to that the chain unite of EHA is more branched than MMA units, which regularity of the chain structures and increased the spacing's between the chains; consequently, the $(\Delta \mathrm{H})$ of copolymer (St/HEA) increased $[28,29]$.
Viscosity behavior of the prepared nanoemulsion polymers: The viscosity of Co-polymer (St/EHA) and Ter-polymer (St/MMA/EHA) nanolatexes were tested. Results have been presented in Table 1.

The results revealed that the viscosity of nano-poly (St/EHA) latex is higher than of nano-poly (St/MMA/EHA) latex. This may be attributed to the fact that the viscosity of a latex at any given total solid content increase with decreasing particle size and with decreasing expansion of the particle-size distribution. When the particle size decrease in monodisperse latex, the average short distance between the surfaces of neighboring particles is also decrease, thus increase the tendency of a particle to interfere with the motion of its neighbors which results in a increasing of latex viscosity.

\section{Characterization of the prepared emulsion polymers in latex paints}

Effect of rheology modifier on water-based paints: A latex paint formulation requires careful adjustment of the rheology. The Interaction/ association between the ingredients of a typical paint formulation coating rheology systems, the balance between ingredients (such as binder, pigments, solvents, dispersants and surfactants) cannot be ignored in order to develop coating rheology systems [30]. A latex paint requires the 
addition of thickeners to achieve the desired rheological behavior. The synthetic thickeners are liquid associative polymers called rheology modifiers that ensure easier usability due to their liquid state [31]. The traditional alkali swellable rheological additives are related to poly acrylic acid (Figure 6). The $\mathrm{pH}$ of the associative polymer as delivers lies 4 , when the $\mathrm{pH}$ is raised around 8 , the polymer swell or uncoil. Associative thickener help to give high quality finish to paints. However, their associative interaction are strongly influence by other formulation ingredients, most important

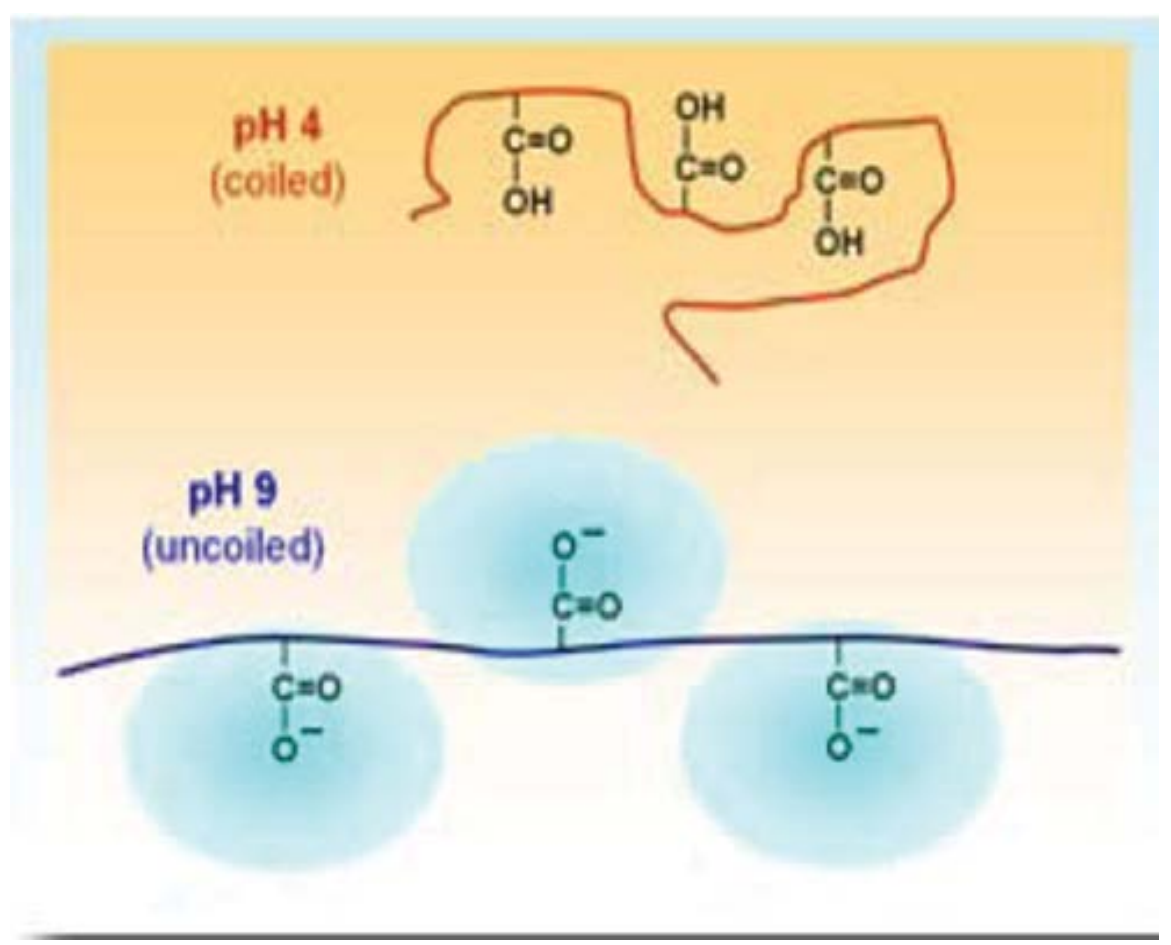

Figure 6: Alkali swelable emulsion polymer chain.

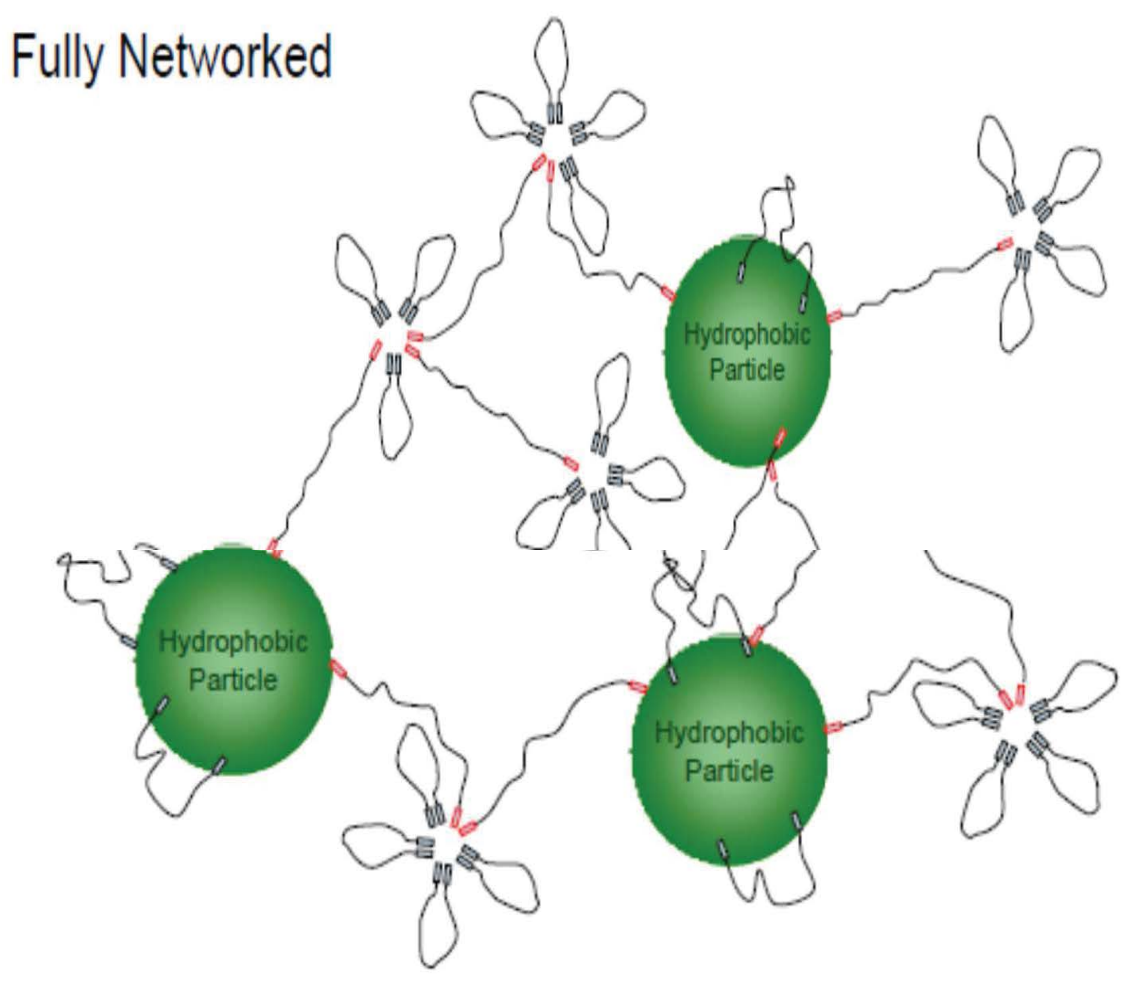

Figure 7: Illustration of a fully networked associative thickening mechanism. 
are the latex particle size [32], high viscosities are achieved with small particle size latexes because of the large available surface area for interaction (Figure 7). In small particle size systems, the efficiency of associative thickener offers best flow, ease of application and sag resistance (Figure 8).

Storage stability test: As a multifunctional paint additive, hydrophobic alkali swellable emulsion (HASE) makes it possible to reduce costs and still obtain performance equal to or better than that of similar paint formulations containing cellulose thickener. In order to check long-term stability of the paints depend on nano-emulsion binder, itis recommended to store them at elevated temperatures $\left(50-60^{\circ} \mathrm{C}\right)$ for two weeks and to check viscosity and color strength afterwards. Insufficient storage stability might lead to flocculation. This is the general term for weakly interaction between associative thickener and binder because; the main ingredient for anti-settling in paint formula is acrylic associative thickener (show Table 2) and the latex has large particle size. Settlement leads to loss of gloss, loss of color strength and settling tendency. The stability of emulsion paints has been obtained as shown in Figure 9.

Influence of Universal color on paint viscosity performance: Universal color formulation often still contain some level of surfactant with an HLB more than 15 may result in good color acceptance and pigment stability. The universal color is recommended for use in tint of coating based on the prepared and commercial latexes (Figure 10). The loss of viscosity with high HLB nonionic surfactants is attributed to surfactant drift with in the formulation. The added surfactant can displace the association from the micelles, the

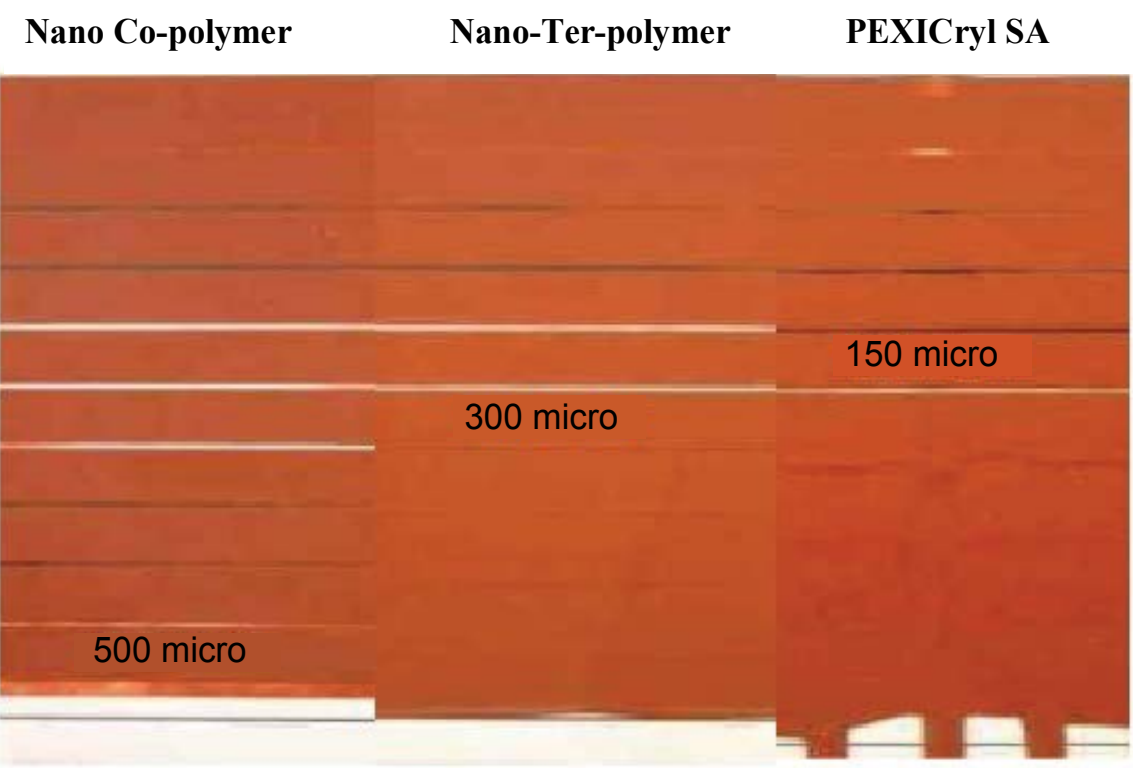

Figure 8: Dramatic paint sag with comercial binder (Right), no paint sag with prepered nano-polymers (left).

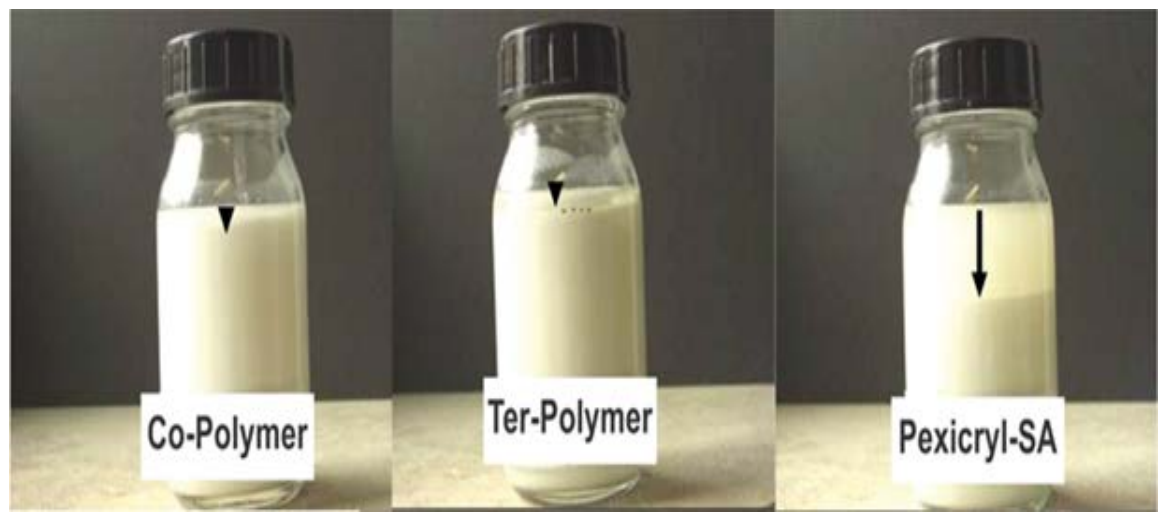

Figure 9: Storage stability of the paints depend on prepered and commercial polymers. 


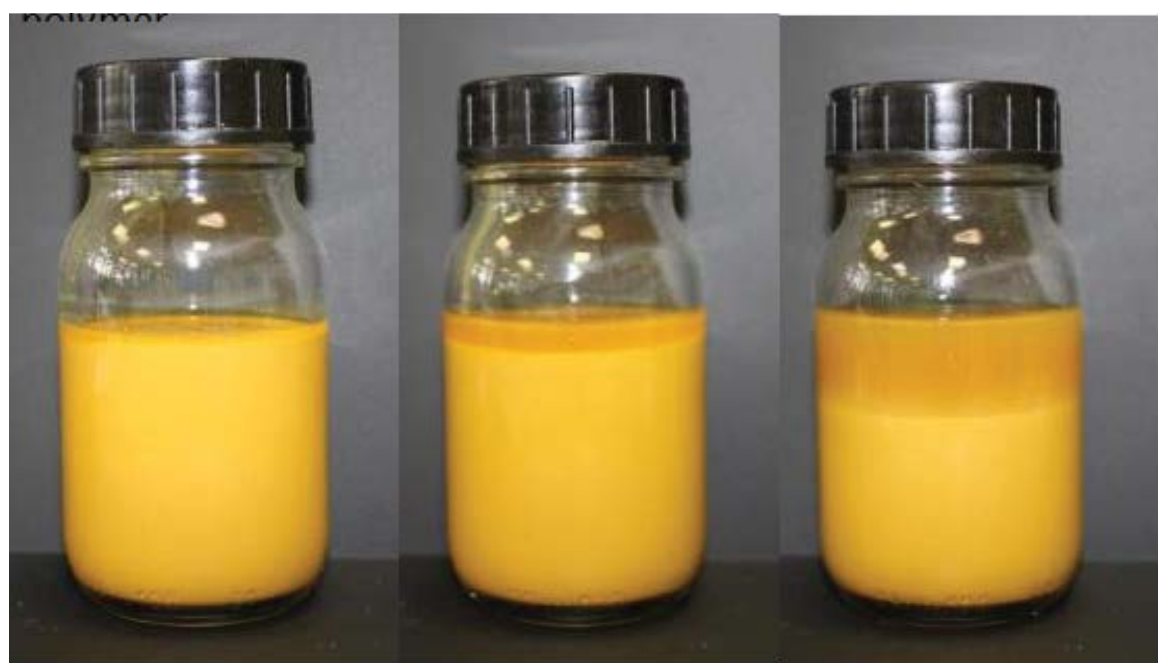

Figure 10: Long-term stability of prepared and commercial latexes with universal colorants.

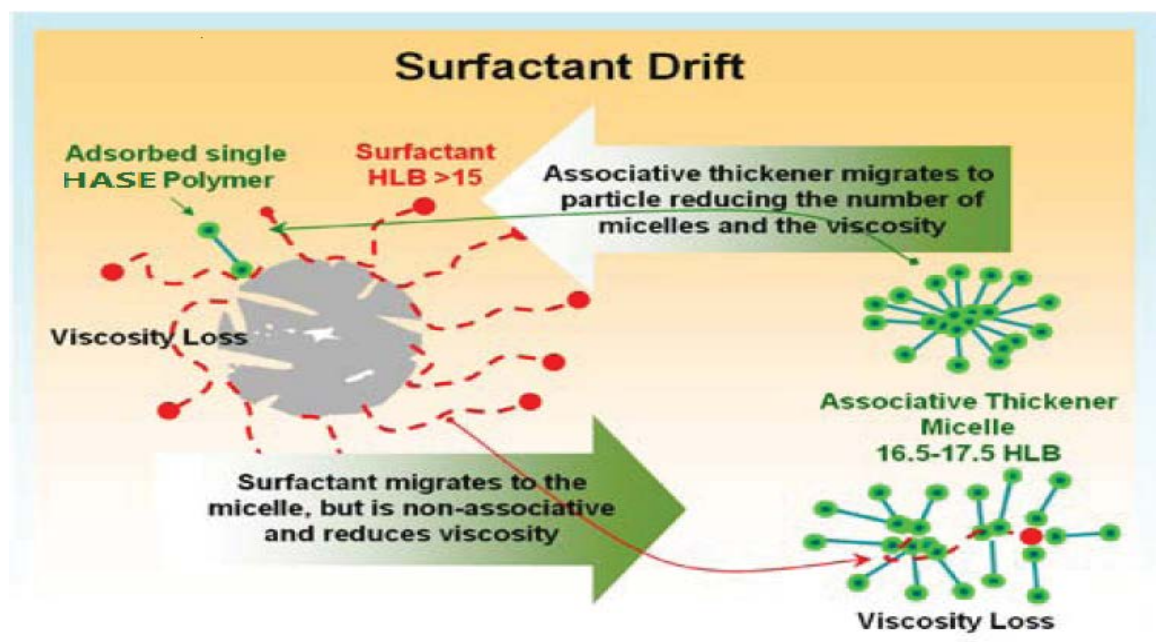

Figure 11: Surfactants displace the assosiation from their micelles.

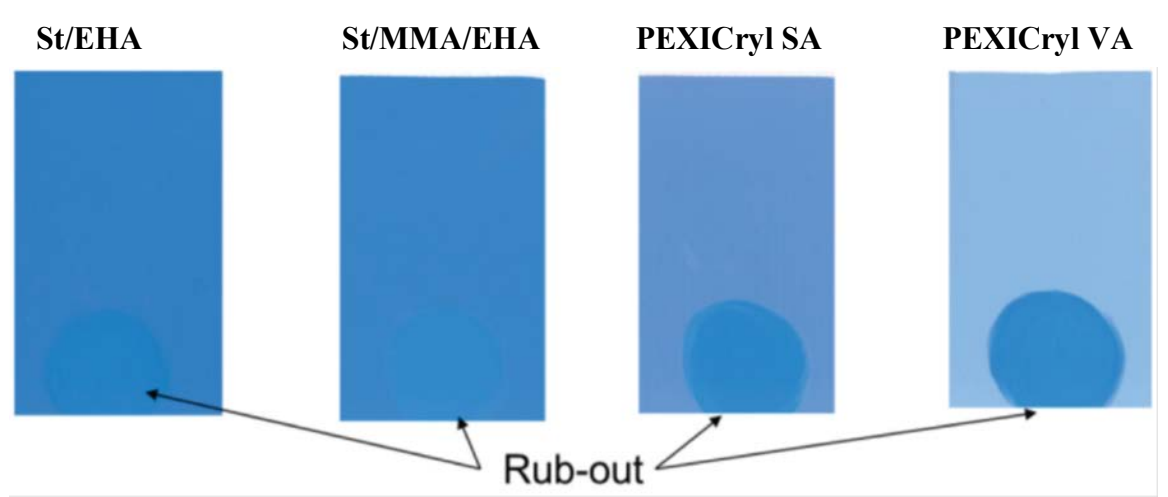

Figure 12: Draw-downs of blue tinted paint with little (left) to strong (right) rub-out.

network weakens and viscosity drops (Figure 11). The surfactant additives show less sensitivity to the prepared Co-polymer and Ter-polymer latexes than do the commercial latex. This might affect not occur immediately but could be observed after several months storage at the formulation gradually equilibrate.

Rub-out test: Rub-out (some people say "rubup") is the color difference between an un-rubbed part of a paint film and a part of the paint film which 
has been rubbed with a finger after application, when it is nearly dry. If there is a big difference, there will be an indication of incompatibility of a colorant with the base paint. This sometimes even happens in readily formulated paints. Figure 12 and Figure 13 showed significantly better performance compared to commercial binders. In the test formula addition of nano-emulsion binder showed good results with a delta $E$ value $<1$ and exhibit a better color acceptance than the other binders.
Water immersion test: The water resistance of the waterborne coatings was mostly determined by the latex polymer hydrophobicity. A coating film created by hard and soft monomers were cooperated to improve the mechanical properties of the coating film during the coating formula designed [33]. The hard monomer St and MMA were used for their desirable hardness and water resistance [7]. Three samples of coating poly (StEHA), poly (St-MMA-EHA) and commercial styrene

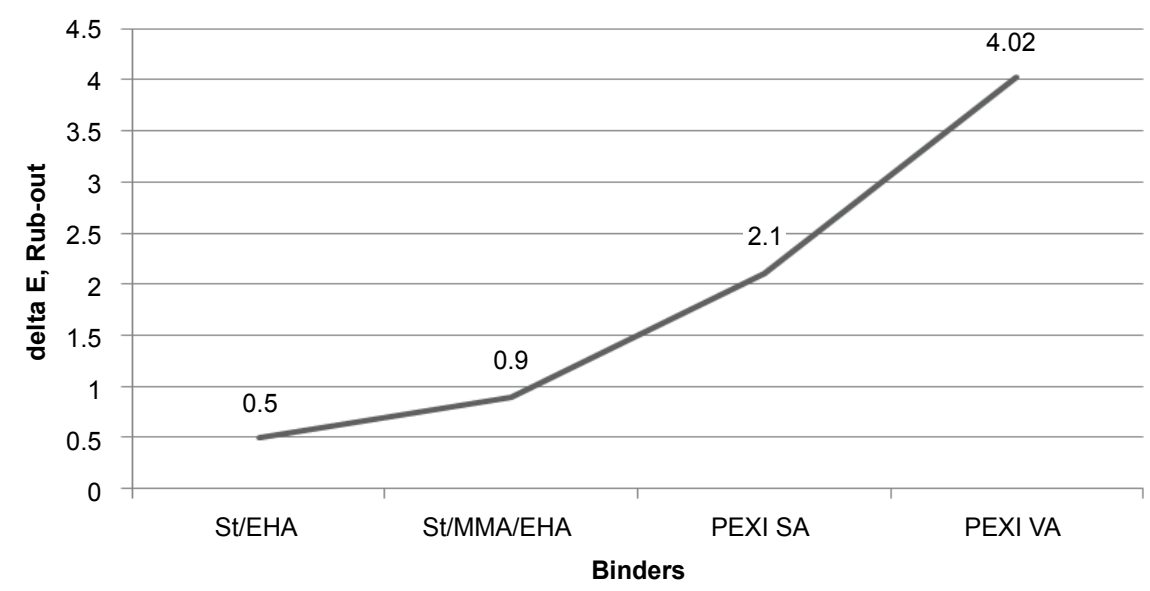

Figure 13: Color acceptance with prepared and commercial polymers.

St/EHA

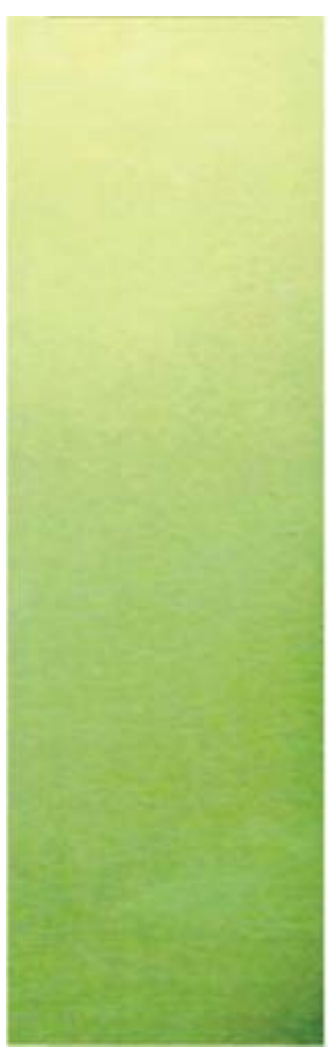

St/MMA/EHA

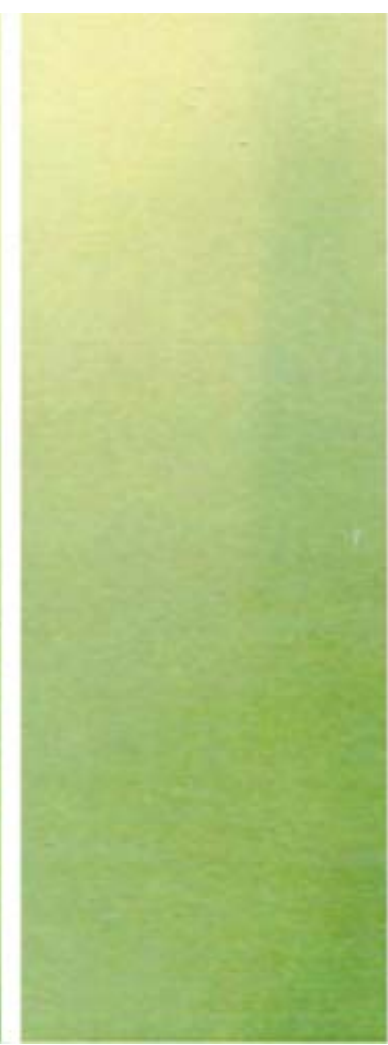

PEXICryl SA

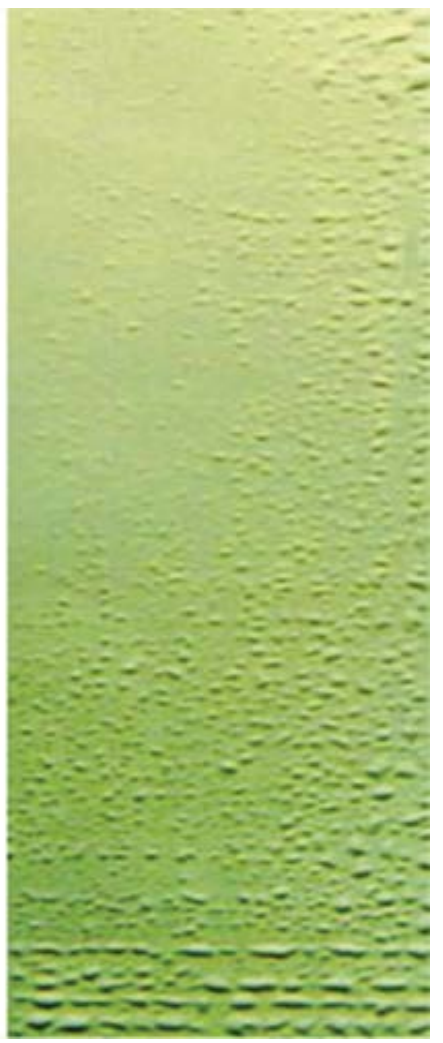

Figure 14: Water immersion test with prepared polymers and commercial styrene acrylate. 
acrylic (PEXICRYLSA) were immersed in distilled water at $25{ }^{\circ} \mathrm{C}$ for $358 \mathrm{~h}$. The nano Co-polymer (St-EHA) can sharply enhance the water resistance of the coating film for its strong hydrophobicity. In addition, MMA in Ter-polymer (St-MMA-EHA) shows less capacity of hydrophobicity than Copolymer (St-EHA) which was fading the color of coating film after water immersion test. The larger particle size of commercial binder (PEXICRYLSA), which weakens the water resistance of film. Figure 14 shows the water immersion test.

Scrub resistance: The effect of the particle size and functional monomer of the latex on the scrub resistance of the coating films was studied for high PVC values only because, the low PVC have enough amount of binder to keep the film ingredients strongly bound. The scrub resistance of the coating films prepared with different latexes varying particle size and functional monomer are showed in Figure 15. It can be observed that those films prepared with the prepared latexes of the smallest particle size presented better scrub resistance. This means that, latexes had high Ingredients binding capacity which is related to higher scrub resistance. In the same way, the compatibility of the ingredients with the commercial latex (PEXICRYL SA) seems to be

Table 5: Gloss for the prepared dry latex paint films and the commercial one.

\begin{tabular}{|l|l|l|}
\hline Latex paint code & $\begin{array}{l}\text { White } \\
\text { coating }\end{array}$ & $\begin{array}{l}\text { Black } \\
\text { coating }\end{array}$ \\
\hline Co-polymer (St/EHA) & 55 & 52 \\
\hline Ter-polymer (St/MMA/EHA) & 52 & 49 \\
\hline PEXICryl SA 5000 & 44 & 40 \\
\hline
\end{tabular}

medium scrub resistance. The compatibility of the paints ingredients with the commercial latex (PEXICRYL VAA) seems to be worse as these blends presented much less scrub resistance, which has low $\mathrm{Tg}$ and reduce minimum film forming temperature, usually suffer from poor scrub.

Gloss measurement: The gloss can be attributed to surface aspects of the painted panels, such as the roughness [34]. The evolution of gloss at $60^{\circ}$ of specular reflection for the paints as function of field exposure and accelerated QUV. Initial gloss values were observed in Table 5 for all the paints systems. During field exposure, there was loss in gloss wherein the faster gloss decay is seen in two well-defined periods of 10 months.

The variations on gloss as function of QUV exposure can be described as follows: During the first Time, the values have not been significantly modified. Afterwards, there was a reduction. From the $200 \mathrm{~h}$ up to the end of the test the values of gloss were modified. In Figure 16, the gloss rating was examined on two types of black and white paint under the influence of the field expose and QUV accelerator. The gloss of Co-polymer (St/EHA) is relatively higher than Ter-polymer (St/MMA/EHA), but Ter-polymer was better in the gloss retention due to the presence of methyl methacrylate. This is because MMA absorbs only trace amounts of light and UV radiation. This small amount of absorbed radiation lacks the energy necessary to break down the molecular bonds within the material. This is a unique property for a polymer, and makes it especially well studied for long term weather resistance $[35,36]$.

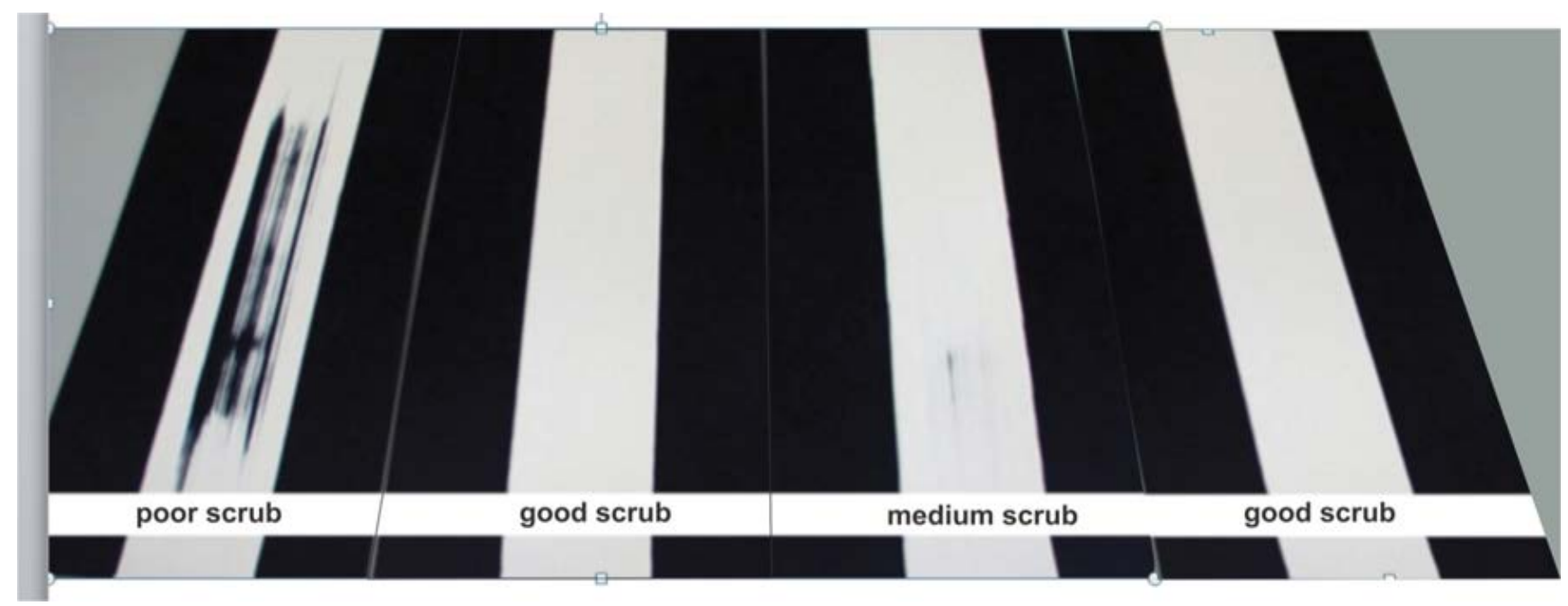

Figure 15: Scrub resistance of the paints depend on prepared and commercial polymers up to 5000 cycles. 


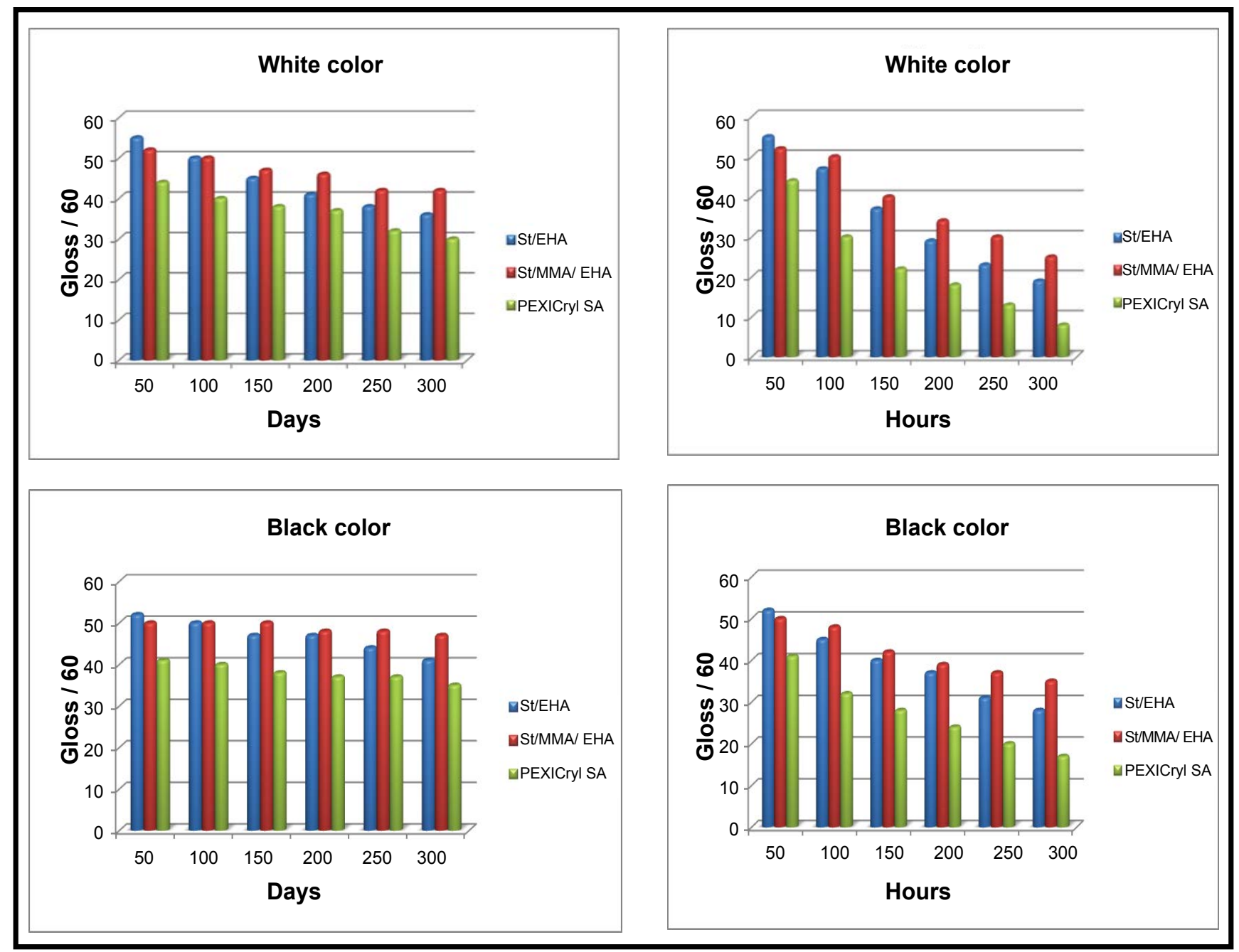

Figure 16: Evolution of specular gloss at $60^{\circ}$ in the course of field exposure (left plot) and accelerated QUV (right plot) for color coatings.

The effect of QUV tester on the Gloss of all prepared dry latex paint films was investigated for $300 \mathrm{~h}$. The latex paint based on (St/MMA/ EHA) shows the lowest change in gloss compared to those based on (St/EHA) and commercial latex (PEXICRYL SA). Based on the results, the latex paint films based on Ter-polymer (St/MMA/EHA) latex did not become yellow for $200 \mathrm{~h}$ in the accelerated weathering test. So, it is recommended that the nanoemulsion high solid content Ter-polymer latex paint will be prospectively used as the exterior coating.

For the white coating, it is suggested a gloss ratings of the prepared polymers rather than the color paints and color perception was moved towards yellow. These changes can be attributed to the high refractive index of $\mathrm{TiO}_{2}$ to the radiation. Indeed, due to the inertness upon UV radiation, $\mathrm{TiO}_{2}$ is one of the most used additives for outdoor applications
[37]. For the black coating; the blackness perception for these coatings was found dependent on the addition of black pigment solution study, the reactivity of carbon black as additive to coatings towards ultraviolet radiation has been investigated and its incorporation into binder improved the UV resistance. These improvements have been attributed to the ability of carbon black to absorb ultraviolet radiation and preserve the polymer matrix $[38,39]$.

\section{Conclusion}

The study aimed to develop novel latexes with good gloss, weather resistance, and thermal stability for coating applications. Latexes were synthesized using a proper feeding policy, proper $\mathrm{Tg}$ and improved dry latex film properties. Styrene acrylate polymers have been prepared by conventional seeded emulsion polymerization by using three monomers namely Styrene, 
2-Ethylhexyl acrylate and Methyl methacrylate. Stable latexes with improved physico-mechanical properties were obtained. Characterizations of the prepared latexes were performed using FTIR, DLS, TEM, and thermal analysis (TGA, DSC). The use of surfactant mixtures, an anionic surfactant (Texapone and Desponil LDPS 25) in combination with a nonionic surfactant (NP30) resulted in more stable colloidal dispersions. Using this combination in the experiments provided small particles size and stability. The effect of the emulsifier mixture concentrations on final conversion of monomer to polymer was studied. The presence of MMA monomer content in the prepared Ter-polymer on the properties of the resulting emulsion latex and their corresponding films was investigated. The water resistance of the prepared nano-emulsion polymers was increased due to hydrophobic effect of St and MMA. The results also showed that improve color development of the coating film. The prepared high solid content Nano Co-polymer (St/ EHA) and Ter-polymer (St/MMA/EHA) latexes were applied as a binder in waterborne house-hold paints and it was found out that the prepared latexes had higher properties than commercial latexes.

\section{References}

1. A Gupta, H BurakEral, T Alan Hattona, Patrick S Doyle (2016) Nanoemulsions: Formation, properties and applications. Soft Matter 12: 2826-2841.

2. TG Mason, J Wilking, K Meleson, C Chang, S Graves (2006) Nanoemulsions: Formation, structure, and physical properties. J Phys Condens Matter 18.

3. T Tadros, P Izquierdo, J Esquena, C Solans (2004) Formation and stability of nano-emulsions. Adv Colloid Interface Sci 108-109: 303-318.

4. D Chenga, Y Wena, X Ana, X Zhua, Y Ni (2016) TEMPOoxidized cellulose nanofibers (TOCNs) as a green reinforcement for waterborne polyurethane coating (WPU) onwood. Carbohydr Polym 151: 326-334.

5. S Veigel, G Grüll, S Pinkl, M Obersriebnig, U Müller, et al. (2014) Improving the mechanical resistance of waterborne wood coatings by adding cellulose nanofibers. React Funct Polym 85: 214-220.

6. LG Ecco, M Fedel, F Deflorian, J Becker, BB Iversen, et al. (2016) Waterborne acrylic paint system based on nanoceria for corrosion protection of steel. Prog Org Coatings 96: 19-25.

7. Z Zhong, Q Yu, H Yao, W Wu, W Feng, et al. (2013) Study of the styrene-acrylic emulsion modified by hydroxyl-phosphate ester and its stoving varnish. Prog Org Coatings 76: 858-862.

8. M Melchiorre Di Crescenzo, E Zendri, M SánchezPons, L Fuster-López, DJ Yusá-Marco (2014) The use of waterborne paints in contemporary murals: Comparing the stability of vinyl, acrylic and styrene-acrylic formulations to outdoor weathering conditions. Polym Degrad Stab 107: 285-293.

9. PA Lovell, MS El-Aasser (1997) Emulsion polymerization and emulsion polymers. Wiley, England.

10.RG Buchheit (2012) Handbook of environmental degradation of materials. ( $2^{\text {nd }} \mathrm{edn}$ ).

11.S Negim, N Aisha, GA Mun, R Iskakov, GS Irmukhametova, et al. (2016) Preparation and characterization of acrylic primer for concrete substrate application. International Journal of Polymer Science 2016: 1-9.

12.AG Sakr, AM Nasser, H Abd El-Wahab, M Abd ElFattah, Abdelzaher EA Mostafa (2018) Preparation and characterization of modified reclaimed asphalt by using styrene - butyl acrylate nanoemulsion copolymer. Egypt J Chem 61: 280-290.

13.H Abd El-Wahab, M Attia, WA Hassan, AM Nasser (2018) Preparation and characterization of nanocopolymers (styrene/2-Ethyl Hexyl Acrylate) based on two different surfactants and use it as a binder for surface coatings. Nanoscience \& Nanotechnology: An Indian Journal 12.

14.HM El-Sherif, AM Nasser, Al Hussin, H Abd El-Wahab, MBM Ghazy, et al. (2017) Nano emulsion binders for paper coating synthesis and application. J Macro Sci 54: 271-287.

\section{5.http://www.iso.org/}

16.ASTM D523-14 (2014) Standard test method for specular gloss, ASTM International, West Conshohocken, PA, USA.

17.ASTM D4213-08 (2012) Standard test method for scrub resistance of paints by abrasion weight loss, ASTM International, West Conshohocken, PA, USA.

18.ASTM D870-15 (2015) Standard practice for testing water resistance of coatings using water immersion, ASTM International, West Conshohocken, PA, USA.

19.ASTM G154-12a (2012) Standard practice for operating fluorescent Ultraviolet (UV) lamp apparatus for exposure of nonmetallic materials, ASTM International, West Conshohocken, PA, USA.

20.Z Yu, B Liu, B Li, Z Pan (1999) Preparation and characterization of MMA-BA-DMAEMA Terpolymer 
latex. Colloids Surf A 153: 31-38.

21.A Zicmanis, T Hamaide, C Graillat, C Monnet, S Abele, et al. (1997) Synthesis of new alkyl maleates ammonium derivatives and their uses in emulsion polymerization. Colloid Polym Sci 275: 1-8.

22.K Wojciechowski, GZ Zukowska, I Korczagin, P Malanowski (2015) Effect of $\mathrm{TiO}_{2}$ on UV stability of polymeric binder films used in waterborne facade paints. Prog Org Coatings 85: 123-130.

23.T Learner (2004) Analysis of modern paints. The Getty Conservation Institute, Los Angeles, USA.

24.F Tharwat Tadros (2013) Emulsion formation and stability. ( $1^{\text {st }}$ edn), Wiley-VCH Verlag $\mathrm{GmbH} \&$ Co. KGaA.

25.HHG Jellinek (1949) Thermal degradation of polystyrene and polyethylene. Part III. J Polym Sci 4: 13-36.

26.MA Abd El-Ghaffar, MH Sherif, A Taher El-Habab (2016) Novel high solid content Nano Siliconated poly (VeoVa-acrylate) Terpolymer latex for high performance latex paints. Chemical Engineering Journal 301: 285-298.

27.Y Lipatov, A Nmerov (1997) Thermodynamic of Polymer blend. Technomic Publ.

28.M Abbasian, M Shahparian, SES Bonab (2012) Well-defined poly (methyl methacrylate) grafted to isotactic polypropylene by metal-catalyzed living radical polymerization. Journal of Elastomers \& Plastics 45: 317-331.

29. HS Moon, BK Ryoo, JK Park (1994) Concurrent crystallization in polypropylene/Nylon-6 blends using maleic anhydride grafted polypropylene as a compatibilizing agent. J Polym Sci-Polym Phys 32: 1427-1435.

30.JJ Florio, DJ Miller (2004) Handbook of coatings additives. ( $2^{\text {nd }}$ edn), Marcel Dekker Inc, New York,
216-269.

31.Dumitru, I Jitaru (2011) Rheology of silylcellulosic derivatives solutions used for tissue regeneration. Rev Chim (Bucuresti) 62.

32.(2008) Elementis Specialties, Rheology handbook. (30 edn), 14-21.

33.Jana Machotová, Jaromír Šňupárek, Luboš Prokůpek, Tomáš Rychlý, Petr Vlasák (2008) Effect of functionalised core-shell microgels prepared by emulsion polymerization on acrylic coatings properties. Prog Org Coat 63: 175-181.

34.M Yonehara, T Matsui, K Kihara, H Isono, A Kijima, et al. (2004) Experimental relationships between surface roughness, glossiness and color of chromatic colored metals. Mater Trans 45: 1027-1032.

35. Osswald, Tim A, Baur, Erwin, Brinkmann, et al. (2006) International plastics handbook, Hanser.

36.E Alfredo, Campo (2006) The complete part design handbook, Hanser.

37.J Miklečić, SL Blagojević, M Petrič, V Jirouš-Rajković (2015) Influence of $\mathrm{TiO}_{2}$ and $\mathrm{ZnO}$ nanoparticles on properties of waterborne polyacrylate coating exposed to outdoor conditions. Prog Org Coatings 89: 67-74.

38.L Gustavo, S Rossi, M Fedel, F Deflorian (2016) Color variation of electrophoretic styrene-acrylic paints under field and accelerated ultraviolet exposure. Materials \& Design 116: 554-564.

39.Ghasemi-Kahrizsangi, H Shariatpanahi, J Neshati, E Akbarinezhad (2015) Degradation of modified carbon black/epoxy nanocomposite coatings under ultraviolet exposure. Appl Surf Sci 353: 530-539. 